\title{
Bidirectional Battery Interface in Standalone Solar PV System for Electrification in Rural Areas
}

\author{
Yuwono Bimo Purnomo ${ }^{1}$, F. Danang Wijaya ${ }^{2}$, Eka Firmansyah ${ }^{3}$
}

\begin{abstract}
In a standalone photovoltaic (PV) system, a bidirectional DC converter (BDC) is needed to prevent the battery from damage caused by $\mathrm{DC}$ bus voltage variation. In this paper, BDC was applied in a standalone solar PV system to interface the battery with a DC bus in a standalone PV system. Therefore, its bidirectional power capability was focused on improving save battery operation while maintaining high power quality delivery. A non-isolated buck-boost topology for the BDC configuration was used to interface the battery with the DC bus. PID controllerbased control strategy was chosen for easy implementation, high reliability, and high dynamic performance. A simulation was conducted using MATLAB Simulink program. The simulation results show that the implementation of the BDC controller can maintain the DC bus voltage to $100 \mathrm{~V}$, have high efficiency at $\mathbf{9 9 . 1 8 \%}$ in boost mode and $99.48 \%$ in buck mode. To prevent the battery from overcharging condition, the BDC stops the charging process and then works as a voltage regulator to maintain the DC bus voltage at reference value.
\end{abstract}

Keyword-Bidirectional DC Converter, Standalone PV, Battery, Power Management, Inverter.

\section{INTRODUCTION}

A standalone solar photovoltaic (PV) system is one of the most promising solutions to overcome the negative impact of burning fossil-fueled plants that are usually used in a rural area. Solar PV has several advantages, such as clean energy and availability in almost every country. However, these advantages have come with drawbacks. The shortcoming of solar energy irradiation is intermittency and availability, which is only available for approximately \pm 12 hours. Therefore, an auxiliary energy source is needed for a stable standalone solar PV operation.

In a traditional standalone PV system, the auxiliary energy source, such as battery, is directly connected to the main DC bus. Therefore, the battery current is uncontrollable. When the system undergoes an interference such as short circuit, it often damages the battery due to a large battery current [1]. With a direct connection to the DC bus, the battery voltage is determined by the DC bus voltage. The number of batteries has to be increased to reach the required voltage for the DC bus. Increasing battery, however, will increase the cost, decrease flexibility and reliability of the system [2]. When problems occurred to the solar PV as the primary energy source, the battery cannot efficiently supply the load demand. Meanwhile, the unstable charging and discharging cycle will reduce the

1,2,3 Department of Electrical and Information Engineering, Faculty of Engineering, Universitas Gadjah Mada; Jl. Grafika No. 2 Kampus UGM Yogyakarta (phone: 0274-552305; e-mail: ${ }^{1}$ yuwono.bimo.p@mail.ugm.ac.id, ${ }^{2}$ danangwijaya@ugm.ac.id, 3eka.firmansyah@ugm.ac.id) battery life. Therefore, a Bidirectional DC Converter (BDC) is needed to interface the battery to the DC bus. It regulates the forward and backward power flow of the battery. The BDC utilization includes but is not limited to electric vehicles [3][5], aerospace application [6], and renewable energy systems [7], [8]. The BDC works as an interface for the primary energy source with the battery. It will reduce the system size, increases the efficiency and performance of the system because two converters are not needed for forward and backward power flow. Furthermore, the BDC operates in varying modes according to the energy balance of the system, which can stabilize the DC bus voltage to ensure normal operation of power supply system [1]. The general structure of BDC can be seen in Fig. 1. Depending on the battery's location, the converter system works as buck-boost converter, and the control system is used to regulate the voltage and current of the system [9].

This paper discusses BDC operation for battery power management system as an auxiliary power source or energy storage for standalone solar PV. The key point of the BDC operation is to regulate the DC bus voltage, control the battery current, ensure optimal power flow of the BDC. Furthermore, the BDC limits the charging and discharging voltage and current operation of the battery to maintain the safety and prolong the battery's lifetime.

\section{BIDIRECTIONAL DC CONVERTER}

\section{A. Topology}

From topology perspective, the BDC can be classified into two main general groups of configurations, namely isolated and non-isolated topologies. The main difference from these configurations is that non-isolated BDC does not use transformers [9], resulting in smaller size and weight, less total cost, and possibly higher efficiency in the conversion step. However, it lacks galvanic isolation and have a smaller gain ratio than isolated configuration.

This paper will focus on using a non-isolated BDC configuration. A non-isolated BDC is basically realized by adding an antiparallel diode to the switch and a controllable switch to the diode. In the non-isolated configuration, the boost-buck type DC-DC converters are the most popular [10]. The basic buck-boost configuration has a voltage conversion ratio described as follows [9].

$$
\frac{V_{H}}{V_{L}}=\frac{1}{1-D}
$$

where $D$ is duty cycle. This BDC configuration can be seen in Fig. 2. The bidirectional operation of the circuit can be explained in two modes as follows. During the step-down operation, $S_{l}$ is operated with required duty cycle, and switch 


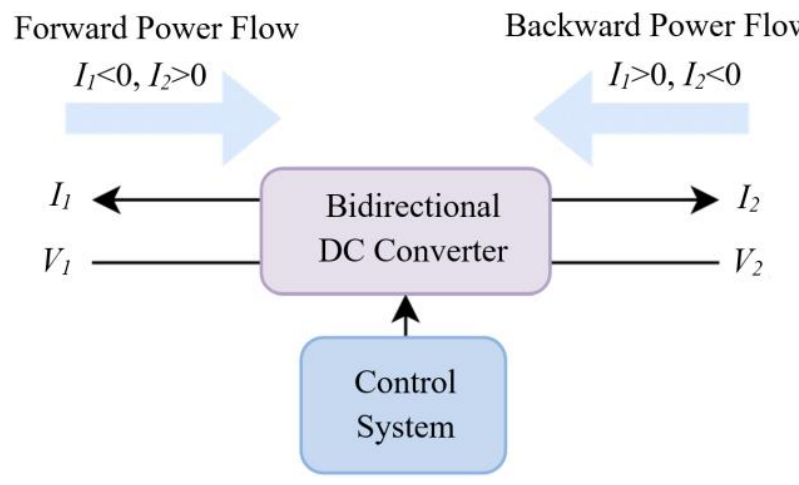

Fig. 1 General structure of BDC.

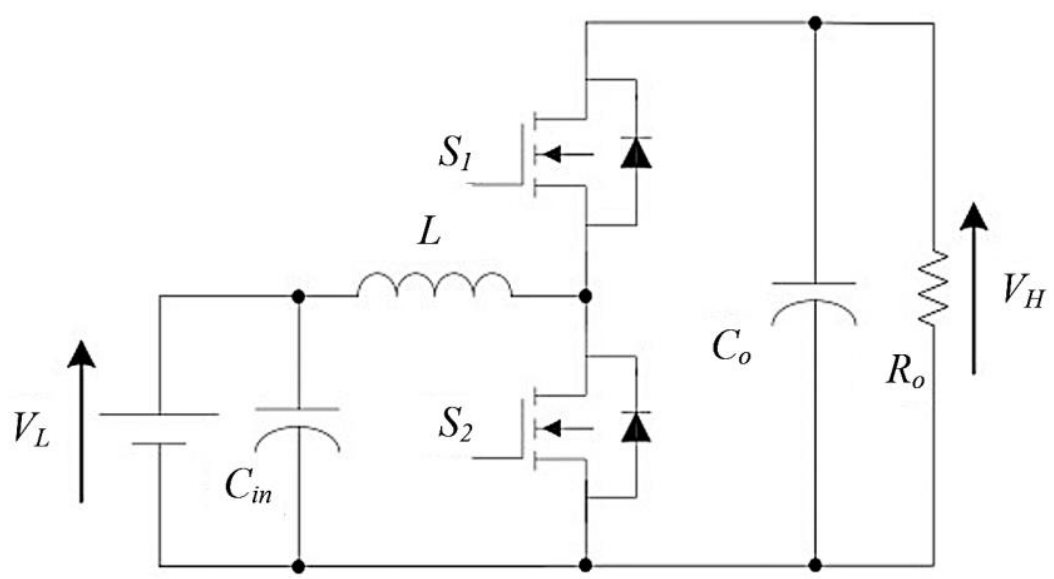

Fig. 2 Non-isolated buck-boost BDC configuration.

$S_{2}$ always off while its body diode is conducting. During the step-up operation, $S_{2}$ is operating and $S_{1}$ is always off.

\section{B. Control Strategy}

The control strategy used in BDC depends on the topology and problems in real-life application. There are two powers transition modes in BDC, from the battery side $\left(L_{V}\right)$ to the DC bus $\left(H_{V}\right)$ and vice versa. In the conventional control strategy, the battery current cannot be controlled because the battery is directly connected to the DC bus. Without proper control, a large transient when power transition cannot be avoided. One of the problems in non-isolated BDC configuration is that the forward and backward power flow must be regulated efficiently.

One of the simplest control strategies in non-isolated BDC configuration is proportional-integral-derivative (PID) controller. PID controller used in many applications and topology and used in many problems such as BDC. In [11], $\mathrm{BDC}$ is used to control the charging and discharging process in DC microgrid system. The PI controllers were implemented in BDC to control the desired current reference signal. The converter operates between DC bus voltage and battery system voltage. The BDC controller can correspond to a power or current reference signal for charging and discharging the battery or can regulate the DC bus voltage in case of an islanded microgrid. Another PID controller application in a multipleinput multiple-output (MIMO) non-isolated BDC enables power transfer capability for multiple inputs [12]. The BDC power flow capability also allows batteries without an additional switch, thus reducing the converter's lifetime size and cost. PI controller is used to regulate the output voltage and the power portion to provide each input source.

The output voltage of the converter is one of the most significant problems in BDC. Two PI controllers for step down (buck) and step up (boost) are commonly used to the control current. Another significant problem in BDC is the continuity of the battery's current, thus influencing the battery lifetime.

\section{CONTROL SYSTEM}

\section{A. DC Boost Converter Controller}

A standalone solar PV typically has intermittent by nature, e.g., due to weather or cloud variations. Therefore, a controlled DC boost converter is needed to regulate the output voltage and track the maximum power point. A maximum power point tracking (MPPT) controller was used with an incremental conductance (IC) algorithm. The IC algorithm output is a duty cycle reference value and directly fed to the boost converter. The switching frequency for the DC boost converter was set to $10 \mathrm{kHz}$. In this paper, varying conditions of solar irradiation were used. Hence, a suitable MPPT controller is needed to give a maximum output power of solar PV in any condition. Fig. 3 shows the MPPT boost converter control.

The boost converter topology was designed to boost fluctuating input voltage in the range of $72-80 \mathrm{~V}$ up to constant 


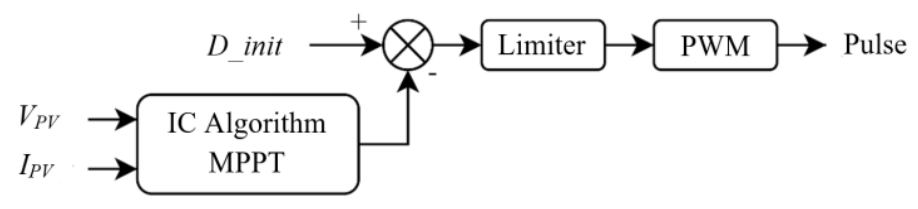

Fig. 3 Boost converter controller using IC algorithm MPPT.

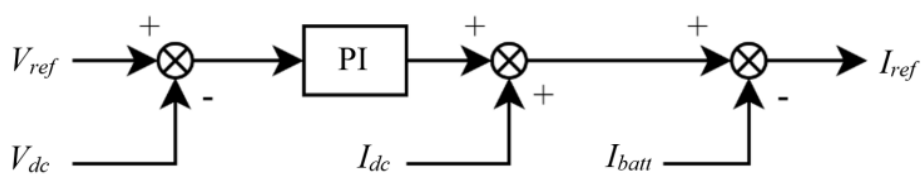

Fig. 4 Voltage control diagram of BDC.
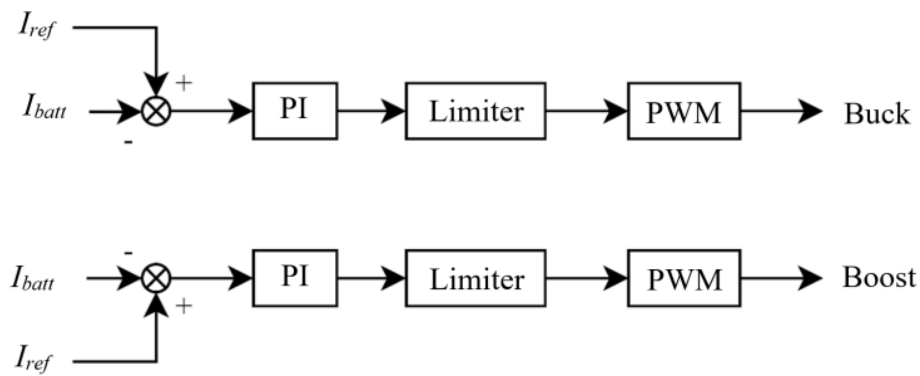

Fig. 5 Current control diagram of BDC.

DC voltage of $110 \mathrm{~V}$. For DC bus stability, inductance and capacitance are described as:

$$
\begin{gathered}
L_{c}=\frac{D(1-D)}{2 f} R \\
C_{c}=\frac{D}{2 f R}
\end{gathered}
$$

where $L c$ is the critical value for inductance, $C_{c}$ is the critical value for the capacitance, $D$ is duty cycle, $f$ is the switching frequency, and $R$ is the load resistance. The boost converter switching frequency was set to $10 \mathrm{kHz}$.

\section{B. BDC Controller}

As mentioned in the previous section, this paper used a PID controller as BDC control strategy. The benefits of using PID control include low cost, easy implementation, high reliability, and high dynamic performance. PI controller was implemented for buck and boost mode as depicted in Fig. 4 and Fig. 5. To ensure stable operation between battery, solar PV, and load, the power reference value can be described as follow.

$$
P_{\text {ref }}=P_{\text {Load }}-P_{P V}
$$

where $P_{\text {Load }}$ is the required power of the system, and $P_{P V}$ is the output power of solar PV. The buck operation mode (charging condition) occurs when the power generated by solar PV is higher than the power demand by the system. Otherwise, the boost operation mode (discharging) occurs when the power generated by solar PV is lower than the power demand by the system. A good BDC filters was designed to ensure low current ripple in order to achieve higher efficiency and prolong the lifetime of the battery. The following equations are used to select the value of the filters [11].

$$
\Delta I_{H V}=\frac{V_{\text {in } D}}{f L}
$$

TABLE I

SYSTEM PARAMETERS

\begin{tabular}{|c|c|c|}
\hline Elements & Parameters & Value \\
\hline \multirow{3}{*}{ Battery } & Rated capacity & $200 \mathrm{Ah}$ \\
\cline { 2 - 3 } & Rated voltage $\left(V_{\text {batt }}\right)$ & $48 \mathrm{~V}$ \\
\cline { 2 - 3 } & Nominal discharge current & $4.35 \mathrm{~A}$ \\
\hline \multirow{3}{*}{ Solar PV } & Max power $\left(P_{P V}\right)$ & $2,799 \mathrm{~W}$ \\
\cline { 2 - 3 } & Max power voltage $\left(V_{m p p}\right)$ & $36 \mathrm{~V}$ \\
\cline { 2 - 3 } & Max power current $\left(I_{m p p}\right)$ & $9.72 \mathrm{~A}$ \\
\hline Load & Max load & $2,200 \mathrm{~W}$ \\
\hline
\end{tabular}

$$
\begin{gathered}
\Delta V_{H V}=\frac{I_{\text {out }} D}{f C} \\
\Delta I_{L V}=\frac{V_{\text {out }}\left(V_{\text {in }}-V_{\text {out }}\right) D}{f L V_{\text {in }}} \\
\Delta V_{L V}=\frac{V_{\text {in }} D(1-D)}{8 L C f^{2}}
\end{gathered}
$$

where (5) and (6) are for the boost side, and (7) and (8) are for the buck side of the BDC.

\section{OPERATION METHODS}

The battery-standalone solar PV system used is composed of a PV array, a boost converter, a lithium-ion battery, a BDC, and a DC load. In the system, the PV array is connected with the DC bus through a DC boost converter. The battery is connected to the DC bus via BDC. The battery-standalone solar PV system is divided into four operation modes, based on the realtime value of $P_{P V}, P_{\text {Load }}$, and state of charge (SOC) of the battery. The efficiency of the system overall can be described as follow.

$$
\eta=\frac{P_{\text {Load }}}{P_{P V}+P_{\text {batt }}} \cdot 100 \%
$$




$$
\eta=\frac{P_{\text {Load }}+P_{\text {batt }}}{P_{P V}} \cdot 100 \%
$$

where $\eta$ is efficiency, $P_{\text {Load }}$ is load power, and $P_{\text {batt }}$ is battery power. Notice that there are two modes of efficiency. Equation (9) is used when PV power produces more power than load demands $\left(P_{P V}>P_{L o a d}\right)$; therefore, the battery is in charging condition and is assumed as load $\left(I_{\text {batt }}<0\right)$. Equation $(10)$ is used when PV power produces less power than load demands $\left(P_{P V}<P_{\text {Load }}\right)$, therefore the battery is in discharging condition and is assumed as auxiliary power $\left(I_{b a t t}>0\right)$.

\section{A. Mode I}

This mode occurs when the SOC of the battery is in the normal range (approximately 20-90\%). The MPPT mode is used to maximize the solar energy absorbed by the PV array. When the solar PV cannot provide the amount of power required by the load, the battery will complement the shortage of power with the battery through BDC. The battery will enter discharging condition, and the BDC will work as boost converter. It generates power flow from the solar PV and battery to the DC bus. Due to the battery works as the auxiliary power source, the battery is assumed as the input of the system.

\section{B. Mode II}

In this mode, when solar energy gradually increases, the solar PV provides more power than the load's power. In this case, the load will be fed by the PV, and the remaining power is used to charge the battery. Therefore, the BDC works in buck converter mode, and the battery will enter charging condition. However, in this mode, the SOC of the battery is needed to remain in the normal range of $20-90 \%$. The battery will receive power from the DC bus to charge. Hence, the battery will be assumed as the output of the system.

\section{Mode III}

In mode III, the battery is assumed to operate in the limit zone of the state of charge. When MPPT is able to charge the battery and the battery SOC reaching $90 \%$, the BDC control will stop charging the battery to protect the battery from overcharge conditions. However, in this condition, the battery cannot be disconnected from the system. Moreover, the battery is used to regulate the DC bus voltage to ensure the stability of the system.

\section{Mode IV}

In this mode, the load power will be assumed to decrease. The solar PV will be set to provide power lower than full load demands same as mode I, so the battery accommodates the shortcoming of the power. When the power decreases, the BDC controller works from boost mode (to discharge the power from the battery) to buck mode (to charge the battery using the remaining power produced by solar PV).

\section{RESULTS AND DISCUSSION}

Simulation was conducted in MATLAB Simulink software. In order to verify the effectivity of BDC controller, a simulation model was designed, and the parameter of the simulation can be seen in Table I. Several variations of solar irradiation were considered to achieve required MPPT condition. In the system, a lithium-ion battery type was selected. Battery capacity should be sized to feed $2,200 \mathrm{~W}$ load, in the absence of solar irradiation (e.g., during nighttime). The medium time for charging the battery is about 5-10 hours; thus, a battery with 200 Ah capacity was chosen. The voltage reference for the DC bus was set to $100 \mathrm{~V}$ in each operation mode. Both IC boost converter MPPT and BDC controller frequency was set to 10 $\mathrm{kHz}$.

\section{A. Simulation Results of Mode I}

Fig. A1 represents the simulation output of the system in mode I. It was assumed that solar PV could not provide enough power to the load $\left(P_{P V}<P_{\text {Load }}\right)$. The solar irradiation was set to $500 \mathrm{~W} / \mathrm{m}^{2}$, and in this case, the battery SOC was in the normal range and set to $60 \%$. The load would be fed by solar PV, and the shortcoming power would be provided by the battery. The BDC works properly as boost converter, and the battery enters discharging condition. When solar irradiation was set to 500 $\mathrm{W} / \mathrm{m}^{2}$, the PV produced $1,400 \mathrm{~W}$ of power, and the battery compensated for the remaining $800 \mathrm{~W}$. The DC bus voltage in this mode reached the reference value in $1.5 \mathrm{~s}$. The simulation result shows the efficiency during steady-state mode is $99.18 \%$.

\section{B. Simulation Results of Mode II}

Fig. A2 represents the simulation results of mode II. Solar PV was assumed to generate more power than power required by the load $\left(P_{P V}<P_{\text {Load }}\right)$. Solar PV was utilized to provide the power to supply the load, and the remaining power was utilized to charge the battery. The solar irradiation was set to $900 \mathrm{~W} / \mathrm{m}^{2}$, and in this case, the battery SOC was in the normal range and set to $60 \%$. The BDC works properly as buck converter, and the battery enters charging condition. When solar irradiation was set to $900 \mathrm{~W} / \mathrm{m}^{2}$, the PV produced $2,500 \mathrm{~W}$ of power, the $2,200 \mathrm{~W}$ was utilized to supply the load, and the remaining 300 W was used to charge the battery. The DC bus voltage in this mode reached the reference value in $1.4 \mathrm{~s}$. The simulation results show the efficiency during steady-state mode is $99.48 \%$.

\section{Simulation Results of Mode III}

Fig. A3 represents the simulation results of mode III. Solar PV was assumed to provide more power than load demand; thus, the battery is in charging condition. When the battery SOC reached $90 \%$, the BDC stopped the charging process of the battery. From the simulation results, at the start of the simulation, the PV generated $2,500 \mathrm{~W}$ of power, and the battery power is shown in Fig. A3(b) is $-300 \mathrm{~W}$. When the battery SOC reached $90 \%$ at $3.8 \mathrm{~s}$, the BDC stopped the charging operation of the battery to prevent the battery from overcharging condition. Then, the BDC worked as voltage regulator to maintain DC bus voltage at $100 \mathrm{~V}$. However, the battery SOC kept increasing because the PV was set to high irradiation. Thus, the power was still flowing across BDC to the battery, although the battery charging power was almost $0 \mathrm{~W}$. The system's efficiency dropped to $88 \%$ due to generated PV power exceeding the power required by the load. 
TABLE II

SIMULATION RESULTS

\begin{tabular}{|c|c|c|c|c|c|c|}
\hline Mode & $\begin{array}{c}\text { Solar } \\
\text { Irradiation }\end{array}$ & $\begin{array}{c}\text { PV Power } \\
\text { Produced }\end{array}$ & Battery Power & Load Power & Efficiency & $\begin{array}{c}\text { SOC } \\
\text { Condition }\end{array}$ \\
\hline I & $500 \mathrm{~W} / \mathrm{m}^{2}$ & $1,400 \mathrm{~W}$ & $800 \mathrm{~W}$ (discharge) & $2,200 \mathrm{~W}$ & $99.18 \%$ & $60 \%$ \\
\hline II & $900 \mathrm{~W} / \mathrm{m}^{2}$ & $2,500 \mathrm{~W}$ & $-300 \mathrm{~W}$ (charge) & $2,200 \mathrm{~W}$ & $99.48 \%$ & $60 \%$ \\
\hline III & $900 \mathrm{~W} / \mathrm{m}^{2}$ & $2,500 \mathrm{~W}$ & $-300 \mathrm{~W}$ (charge) to 0 W (stop \\
charging) & $2,200 \mathrm{~W}$ & $\begin{array}{c}99.48 \% \\
88 \%\end{array}$ & $90 \%$ \\
\hline IV & $500 \mathrm{~W} / \mathrm{m}^{2}$ & $1,400 \mathrm{~W}$ & $800 \mathrm{~W}$ (discharge) to -400 W \\
(charging) & $2,200 \mathrm{~W}$ to $1,000 \mathrm{~W}$ & $\begin{array}{c}95.6 \% \text { to } \\
71.54 \%\end{array}$ & $60 \%$ \\
\hline
\end{tabular}

\section{Simulation Results of Mode IV}

Fig. A4 represents the simulation results of mode IV. The solar PV irradiation was set to $500 \mathrm{~W} / \mathrm{m}^{2}$ and generated 1,400 $\mathrm{W}$ of power. At the start of the simulation, the power required by the load was set to $2,200 \mathrm{~W}$, then it was lowered to $1,000 \mathrm{~W}$ at $4 \mathrm{~s}$. The BDC works properly to track the decreased power demands and decrease the power sent to the DC bus. The BDC was able to respond in this condition and changed the battery condition from discharging to charging. The DC bus voltage was increased to $105 \mathrm{~V}$ and needed $1.5 \mathrm{~s}$ to reach steady-state condition at $100 \mathrm{~V}$.

\section{E. Discussion}

From the results shown above, the BDC worked properly as buck or boost mode, and the battery power response was good in each mode. If one condition requires battery power to discharge and the battery SOC lower than 20\%, it is recommended to shut down the system for safe operation and prevent the battery from damage caused by over discharge condition. Several strange behaviors at the beginning of the simulation were due to all parts of the system (load, PV, and battery) connected simultaneously. During the transition, the system needed $\pm 1.5 \mathrm{~s}$ before entering steady-state condition. The DC bus voltage was maintained at a reference value of 100 $\mathrm{V}$ at each operation mode. The efficiency of each operation mode is shown in Table II, which is the system efficiency when each mode is in steady-state mode. In each mode, the efficiency reached more than $99 \%$ except in mode III, when BDC stopped the charging operation of the battery. Reaching high efficiency in each mode means an increase in the reliability of the system, as the battery can provide the shortcoming power when PV cannot produce enough power or directly change to charging mode when PV produces more power than load demands. The high efficiency proves that the BDC can manage the battery to works as auxiliary power or works as a storage device.

\section{CONCLUSION}

In this study, a PI control based of BDC controller was designed and tested. To investigate the validity of the power management, a variation of solar irradiation, load, and battery SOC was set, and the power output response of each mode was presented. Results showed that the implementation of BDC controller could be flexible, highly reliable, also have high efficiency. The controller works independently at each condition to regulate forward and backward power flow, thus maintain the power balance of the system. The abnormal initial condition of the simulation is due to all devices connected simultaneously.

\section{REFERENCES}

[1] C. Wang, W. Chen, S. Shao, Z. Chen, B. Zhu, and H. Li, "Energy Management of Stand-Alone Hybrid PV System," Energy Procedia, Vol. 12, pp. $471-479,2011$.

[2] A. Mirzaei, M. Forooghi, A.A. Ghadimi, A.H. Abolmasoumi, and M.R. Riahi, "Design and Construction of a Charge Controller for Standalone PV/Battery Hybrid System by Using a New Control Strategy and Power Management," Solar Energy, Vol. 149, pp. 132-144, Jun. 2017.

[3] P. He and A. Khaligh, "Comprehensive Analyses and Comparison of 1 KW Isolated DC-DC Converters for Bidirectional EV Charging Systems," IEEE Transactions on Transportation Electrification, Vol. 3 , No. 1, pp. 147-156, Mar. 2017.

[4] V. Monteiro, J.G. Pinto, and J.L. Afonso, "Operation Modes for the Electric Vehicle in Smart Grids and Smart Homes: Present and Proposed Modes," IEEE Transactions on Vehicular Technology, Vol. 65, No. 3, pp. 1007-1020, Mar. 2016.

[5] O. Erdinc, N.G. Paterakis, T.D.P. Mendes, A.G. Bakirtzis, and J.P.S Catalao, "Smart Household Operation Considering Bi-Directional EV and ESS Utilization by Real-Time Pricing-Based DR," IEEE Transactions on Smart Grid, Vol. 6, No. 3, pp. 1281-1291, May 2015.

[6] L. Tarisciotti, A. Costabeber, C. Linglin, A. Walker, and M. Galea, "Evaluation of Isolated DC/DC Converter Topologies for Future HVDC Aerospace Microgrids," IEEE Energy Conversion Congress and Exposition (ECCE), 2017, pp. 2238-2245,

[7] F. Kardan, R. Alizadeh, and M.R. Banaei, "A New Three Input DC/DC Converter for Hybrid PV/FC/Battery Applications," IEEE Journal of Emerging and Selected Topics in Power Electronics, Vol. 5, No. 4, pp. 1771-1778, Dec. 2017.

[8] L. Wang, Q. Vo, and A.V. Prokhorov, "Stability Improvement of a Multimachine Power System Connected with a Large-Scale Hybrid Wind-Photovoltaic Farm Using a Supercapacitor," IEEE Transactions on Industry Applications, Vol. 54, No. 1, pp. 50-60, Jan.-Feb. 2018.

[9] S.A. Gorji, H.G. Sahebi, M. Ektesabi, and A.B. Rad, "Topologies and Control Schemes of Bidirectional DC-DC Power Converters: An Overview," IEEE Access, Vol. 7, pp. 117997-118019, Aug. 2019.

[10] K. Tytelmaier, O. Husev, O. Veligorskyi, and R. Yershov, "A Review of Non-isolated Bidirectional DC-DC Converters for Energy Storage Systems," International Young Scientists Forum on Applied Physics and Engineering, 2016, pp. 22-28.

[11] M. Saleh, Y. Esa, Y. Mhandi, W. Brandauer, and A. Mohamed, "Design and Implementation of CCNY DC Microgrid Testbed," IEEE Industry Applications Society Annual Meeting, 2016, pp. 1-7.

[12] K. Varesi, S.H. Hosseini, M. Sabahi, E. Babaei, and N. Vosoughi, "Performance and Design Analysis of an Improved Non-isolated Multiple Input Buck DC-DC Converter," IET Power Electronics, Vol. 10, No. 9, pp. 1034-1045, Mar. 2017. 
APPENDICES

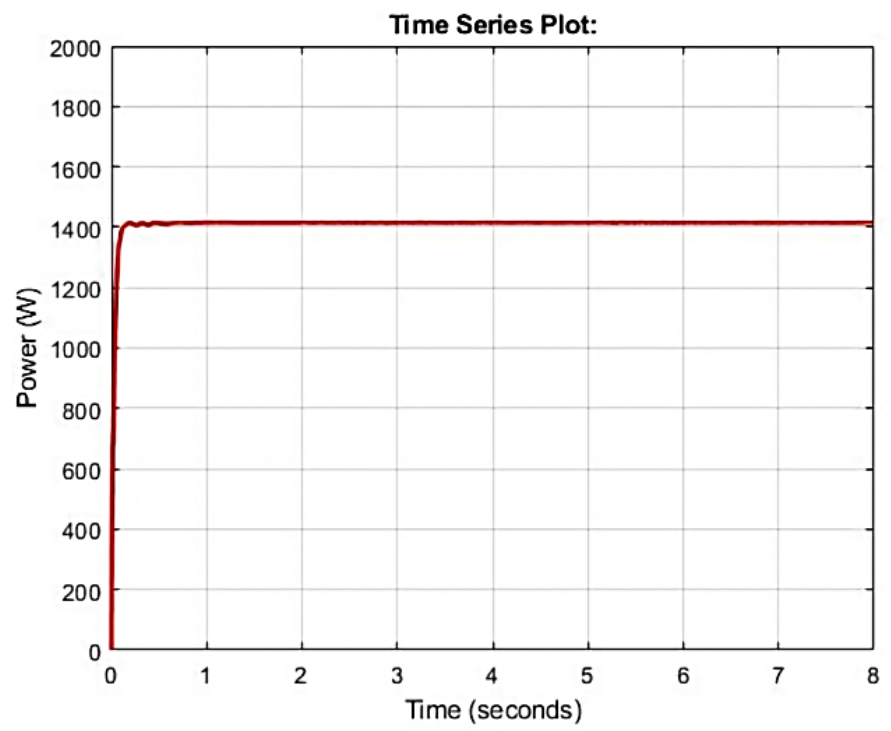

(a)

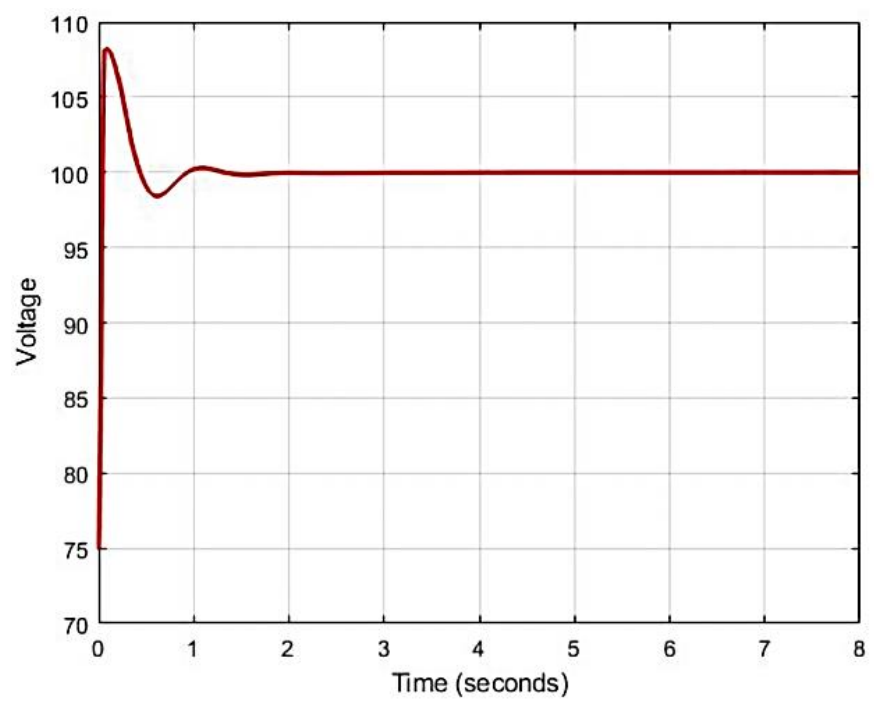

(c)

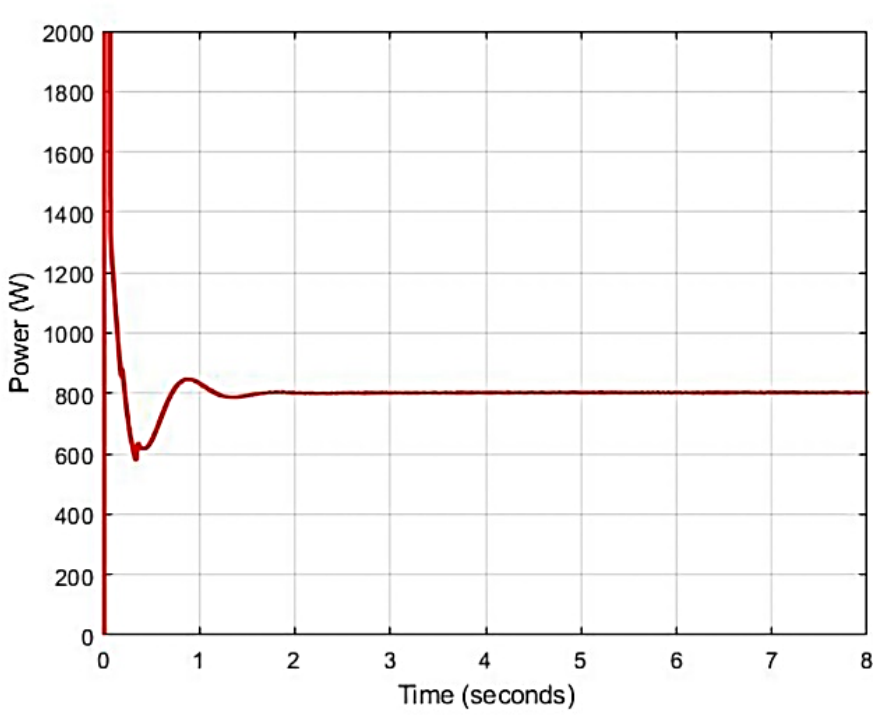

(b)

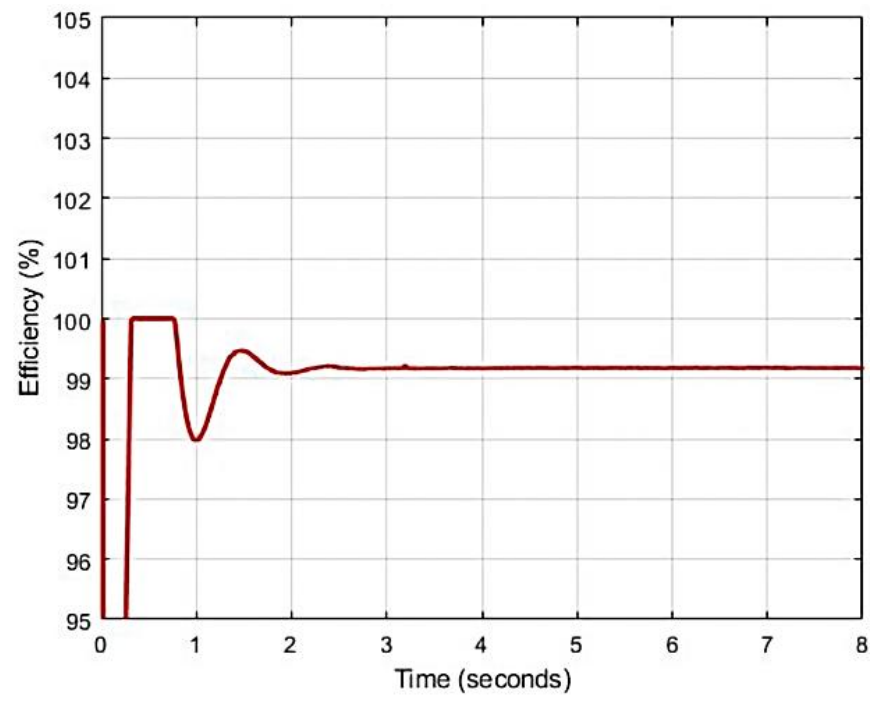

(d)

Fig. A1 Simulation results of mode I, (a) $P_{P V}$, (b) $P_{b a t t}$, (c) DC bus voltage, and (d) efficiency. 


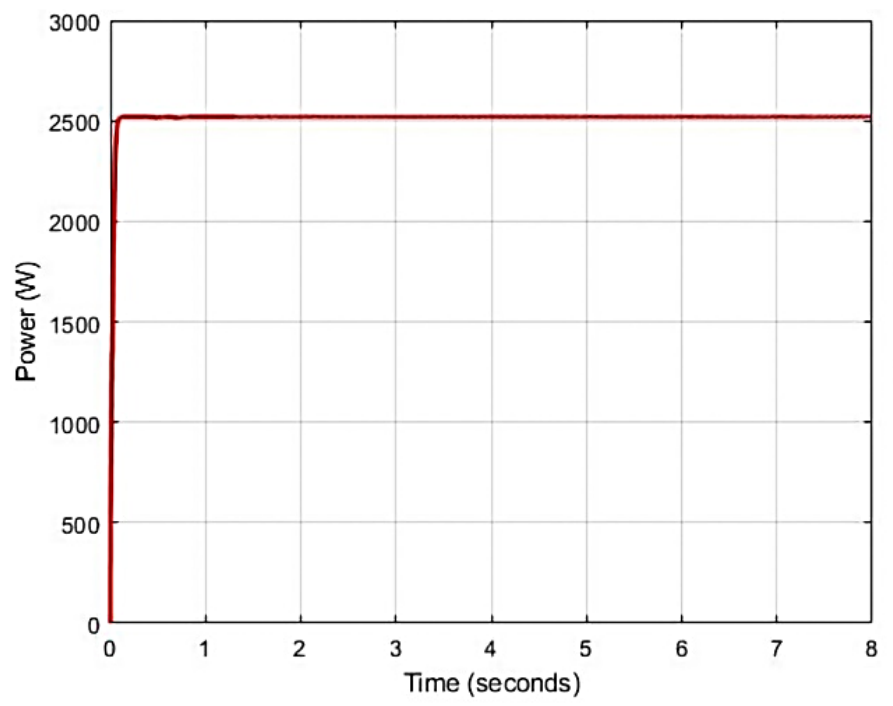

(a)

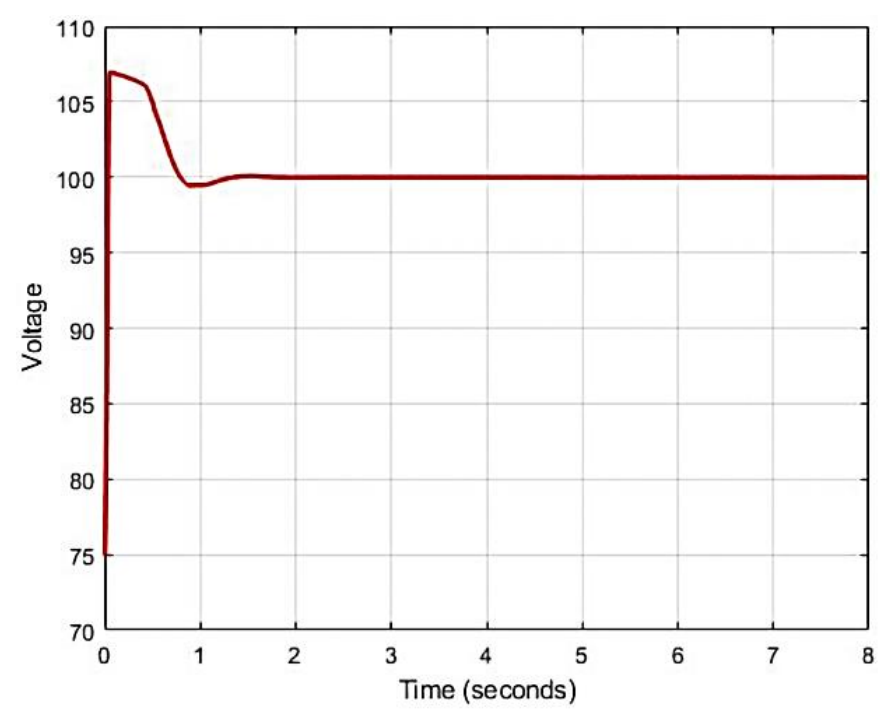

(c)

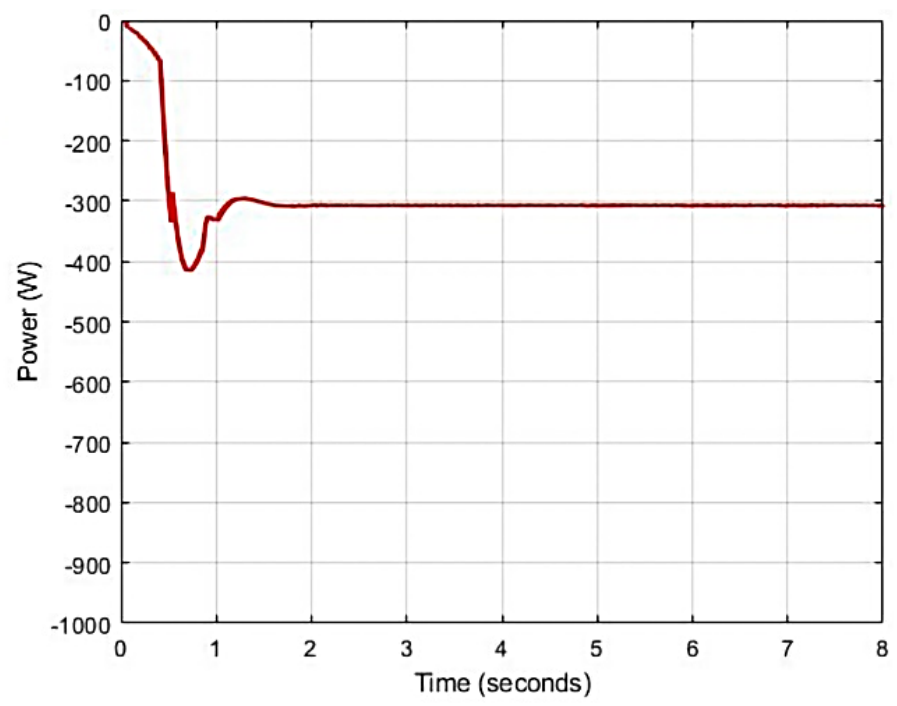

(b)

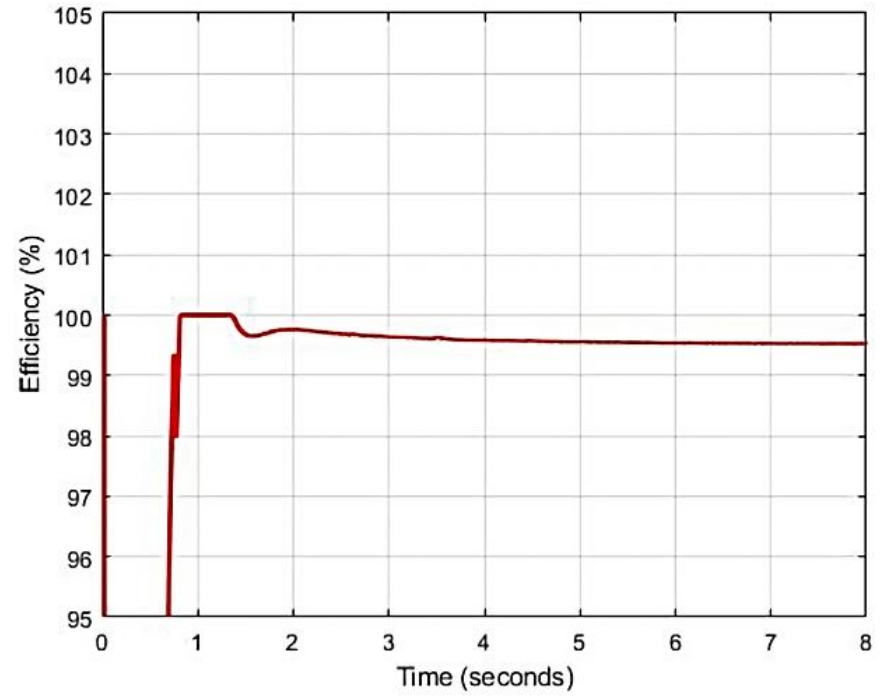

(d)

Fig. A2 Simulation results of mode II, (a) $P_{P V}$, (b) $P_{b a t t}$, (c) DC bus voltage, and (d) efficiency. 


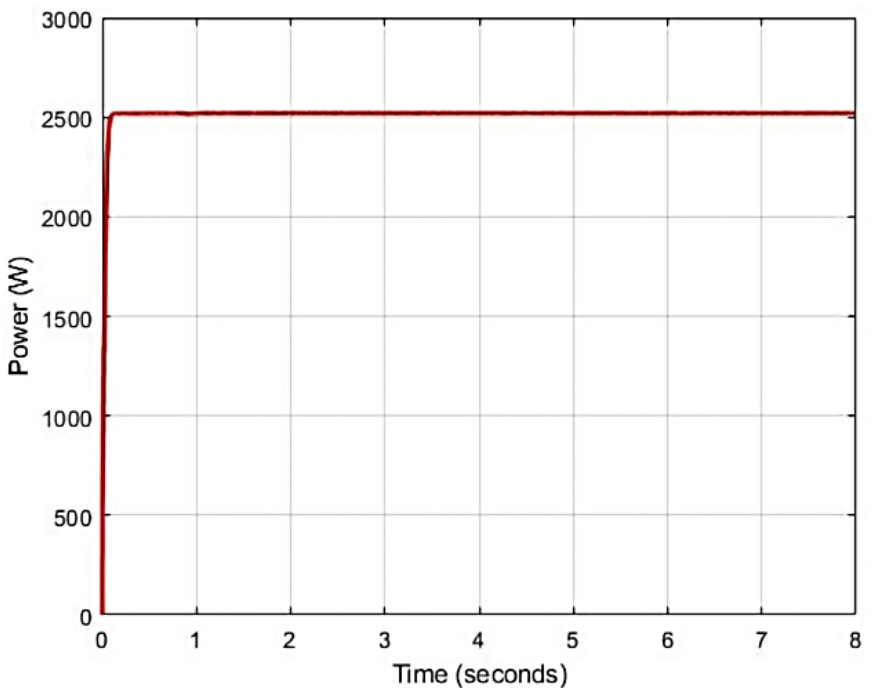

(a)

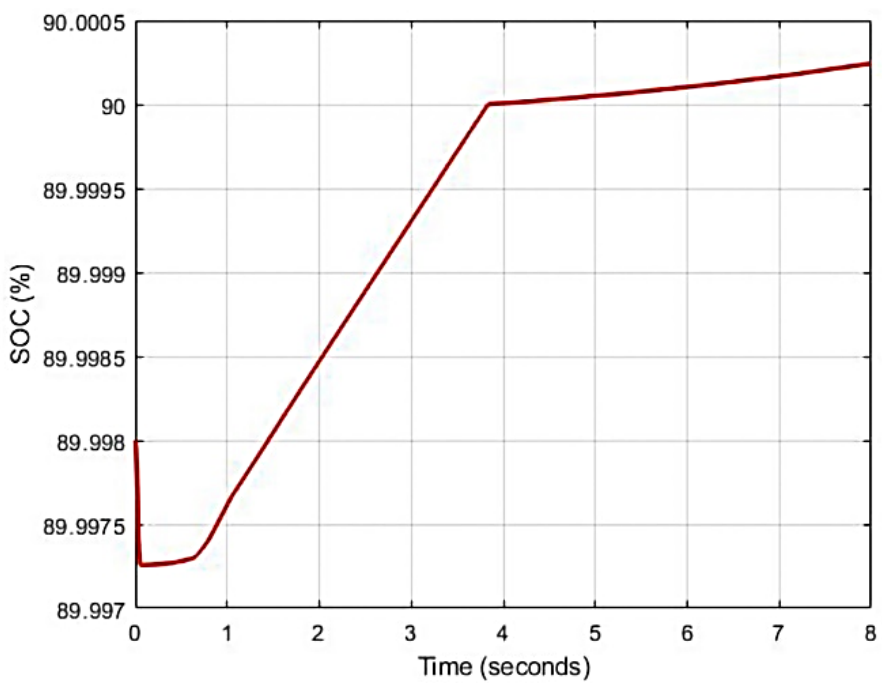

(c)

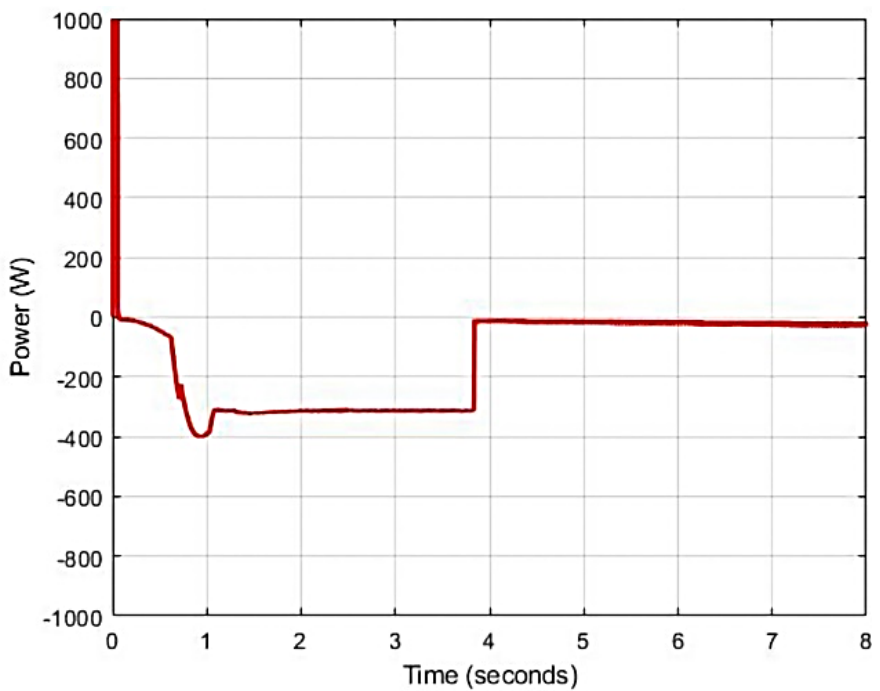

(b)

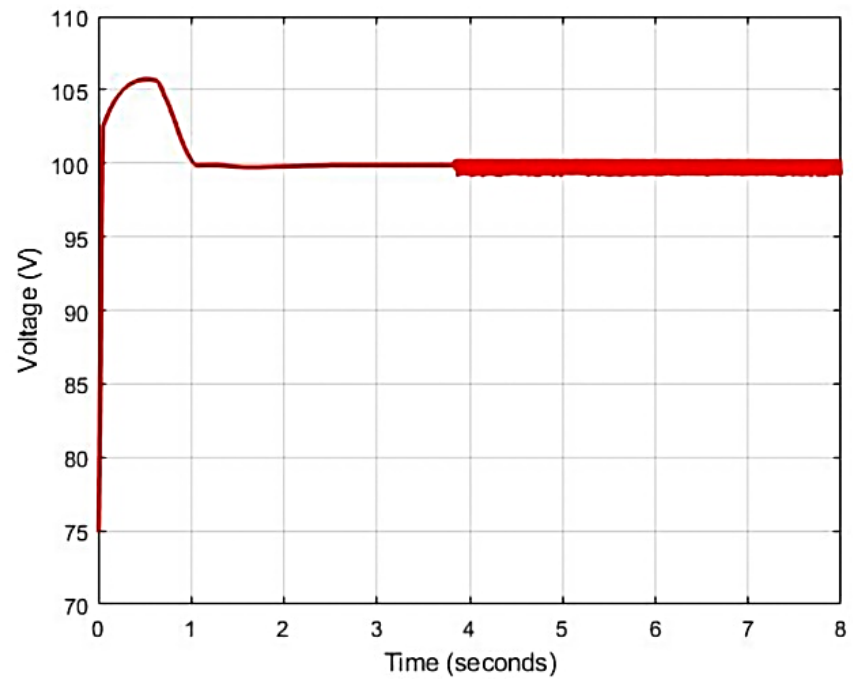

(d)

Fig. A3 Simulation results of mode III, (a) $P_{P V}$, (b) $P_{\text {batt }}$, (c) battery SOC, and (d) DC bus voltage. 


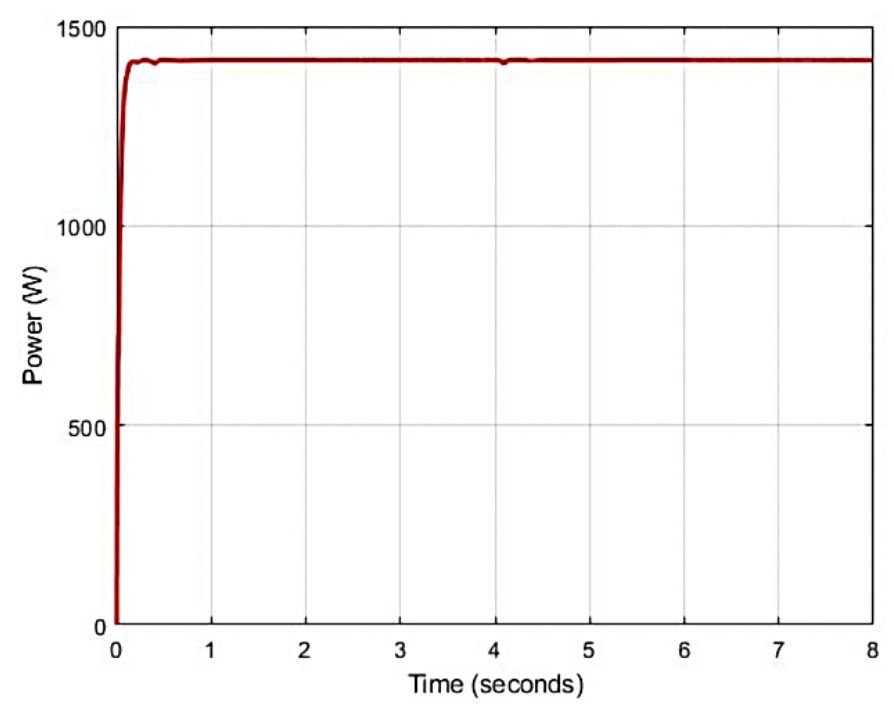

(a)

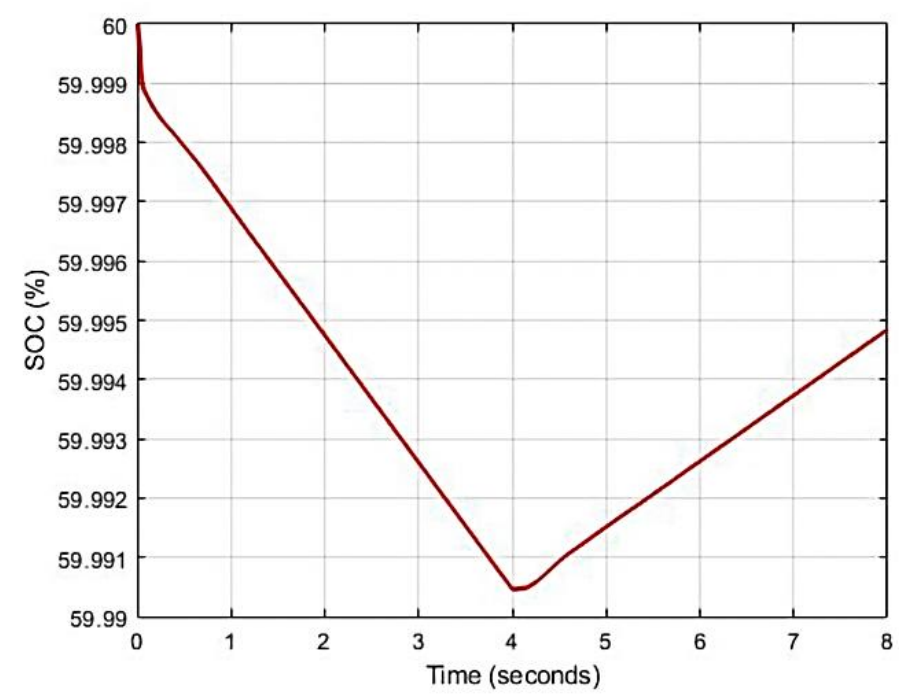

(c)

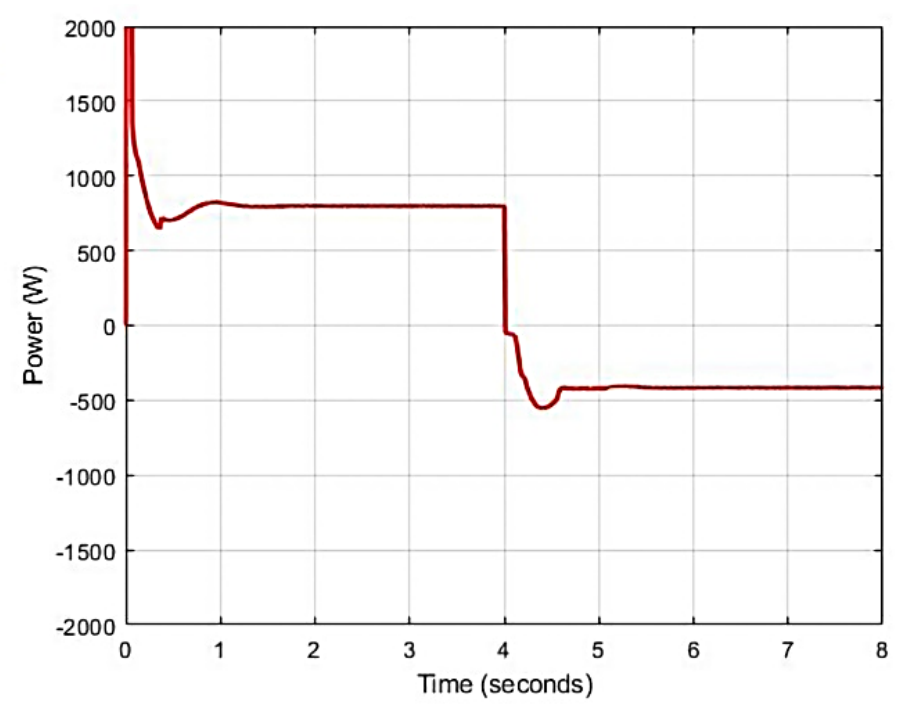

(b)

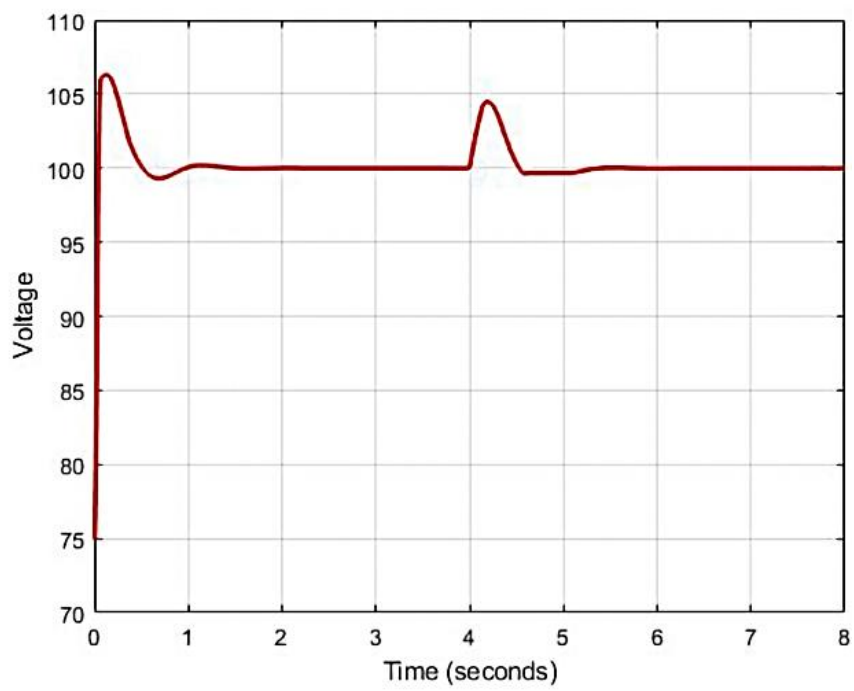

(d)

Fig. A4 Simulation results of mode IV, (a) $P_{P V}$, (b) $P_{\text {batt }}$, (c) battery SOC, and (d) DC bus voltage. 